Proc. Indian Acad. Sci. (Chem. Sci.), Vol. 89, Number 1, February 1980, pp. 17-23. (C) Printed in India.

\title{
4-Nitro 2-picoline-1-oxide complexes of lanthanide perchlorates
}

\author{
N S NAVANEETHAM and S SOUNDARARAJAN \\ Department of Inorganic and Physical Chemistry, Indian Institute of Science, \\ Bangalore 560012 \\ MS received 19 May 1979 ; revised 29 December 1979
}

\begin{abstract}
Nitro 2-picoline-1-oxide (NPicO) complexes of the formulae $\mathrm{La}(\mathrm{NPicO})_{5}$ $\left(\mathrm{ClO}_{4}\right)_{3}, \mathrm{Ln}_{2}(\mathrm{NPiCO})_{9}\left(\mathrm{ClO}_{4}\right)_{6}(\mathrm{Ln}=\mathrm{Pr}, \mathrm{Nd}$, and $\mathrm{Gd})$ and $\mathrm{Ln}(\mathrm{NPiCO})_{4}\left(\mathrm{ClO}_{3}\right)_{3}$ $(\mathrm{Ln}=\mathrm{Tb}$, Dy, Ho and $\mathrm{Yb}$ ) have been synthesised and characterised by analysis, electrolytic conductance, infrared, proton NMR and electronic spectral data. A tentative coordination number of 6 for all the complexes have been assigned.
\end{abstract}

Keywords. Lanthanide perchlorates; 4-Nitro 2-picoline-1-oxide. electrolytic conductance; electronic spectra.

\section{Introduction}

Among the disubstituted pyridine-1-oxides only 2,6-lutidine-1-oxide (2,6 LutO) has been used for complexing with lanthanide salts (Koppikar et al 1978). 2,6-LutO complexes of lanthanide perchlorates have the composition $\operatorname{Ln}\left(2,6-\mathrm{Luto}_{3}\right.$ $\left(\mathrm{ClO}_{4}\right)_{3}$ (Koppikar and Soundararajan 1975) and $\mathrm{Ln}(2,6-\mathrm{LutO})_{5}\left(\mathrm{ClO}_{4}\right)_{3}$ (Karayannis et al 1974), suggesting that the steric hindrance due to the methyl groups at 2 and 6 positions of the pyridine-1-oxide moiety, is sufficiently large to stabilise complexes with lower $\mathrm{L}: \mathrm{M}$ compared to that in the corresponding complexes of pyridine-1-oxide. We have now initiated a systematic programme involving adducts of lanthanide salts with 2,4-disubstituted pyridine-1-oxides. As a part of such studies, we have reported 2,4-lutidine-1-oxide (2,4-LutO) complexes of lanthanide perchlorates with the compositions $\operatorname{Ln}_{2}(2,4 \mathrm{LutO})_{15}\left(\mathrm{ClO}_{4}\right)_{6}$ and $\mathrm{Ln}_{2}(2,4-\mathrm{LutO})_{13}\left(\mathrm{ClO}_{4}\right)_{8}$ (Navaneetham and Soundararajan 1979). In continuation of such studies, we have now prepared the complexes of 4-nitro 2-picoline-1-oxide with lanthanide perchlorates. We report in this papen the preparation of the complexes and their characterisation by analytical, IR, NMR, conductance and clectronic spectral data. The physico-chemical properties of the complexes have been compared with those of the corresponding complexes of 2,4-LutO.

\section{Experimental}

\subsection{Materials}

2-Picoline was obtained from S.D's Laboratory, Bombay. Lanthanide oxides (99.9\% pure) were obtained from Indian Rare Earths Ltd., Kerala State. All 
other chemicals used were of reagent grade. The solvents were purified by standard methods.

\subsection{Preparation of the ligand NPicO}

2-Picoline-1-oxide was prepared ascording to the method given by Ochiai (1953) by the N-oxidation of 2-picoline. NPicO was prepared by the nitration of 2-picoline-1-oxide as deszribed by Katritzky et al (1957) for the preparation of 4-nitro pyridine-l-oxide, and was purifted by recrystallisation from acetone (m.p. $153^{\circ} \mathrm{C}$ lit. $\left.154^{\circ} \mathrm{C}\right)$.

\subsection{Preparation of the hydrated lanthanide perchlorates}

The hydrated lanthanide perchlorates were prepared by dissolving the corresponding oxides in a little less than the required quantity of $50 \%$ perchloric acid and evaporating the filtrate on a steam bath.

\subsection{Preparation of the lanthanide perchlorate complexes of NPicO}

Hydrated lanthanide perchlorate $(0.6 \mathrm{mM})$ dissolved in ethyl acetate $(5 \mathrm{ml})$ was added drop by drop to a boiling solution of NPicO $(6 \mathrm{mM})$ in chloroform with vigorous stirring. B riling and stirring was continued till a solid was formed. The conplex was filtered hot through a sintered crucible and washed 3-4 times with hot chloroform and finally with ether. While the complex was still covered with a little ether, the crucible was transferred to a vacuum desiccator, and the com. plex dried over phosphorous (V) oxide.

\subsection{Analyses}

The metal content of the complexes was estimated by EDTA titrations using xylenol orange as the indicator (Kolthoff and Ewing 1963). The perchlorate was estimated by gravimetric precipitation with nitron as described by Welcher (1947). The ligand NPicO was analysed spectrophotometrically at $350 \mathrm{~nm}$-by measuring the optical densities on a Beckmann Model-25 spectrophotometer. The analytical data are presented in table 1.

\subsection{Physical methods}

The IR spectra of the complexes and the ligand in $\mathrm{KBr}$ pellets in the region $400-4000 \mathrm{~cm}^{-1}$ were recorded on a Carl-Zeiss-UR-10 infrared spectrophotometer. Proton NMR spectra of the ligand and the La-complex were recorded on a-Varian $\mathrm{T}-60$ instrument using $\mathrm{CH}_{3} \mathrm{CN}$ as solvent and TMS as the internal standard.

Electronic spectra of $\mathrm{Nd}$ and $\mathrm{Ho}$ complexes in nitromethane were recorded, in the visible region on a Beckmann Model-25 spectrophotometer.

Conductance measurements in nitromethane were carried out in a Siemen's conductivity bridge using an immersion cell (type LTA), previously calibrated with standard $\mathrm{KCl}$ solution. The concentrations of the solutions used are given in table 1 . 


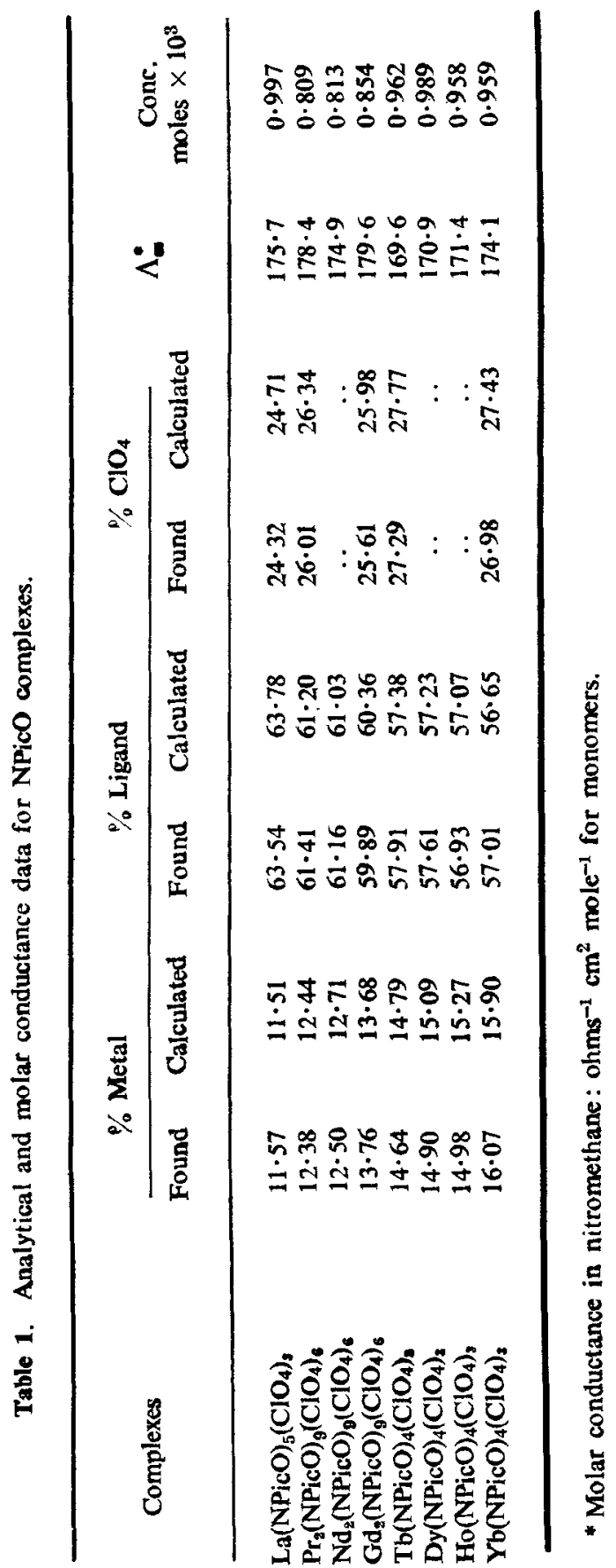




\section{Results and discussion}

All the complexes are hygrossopic and are soluble in solvents like nitromethane, acetonitrile, but insoluble in nitrobenzene, chloroform and benzene. The colours of the complexes resemble the yellow colour of the ligand.

Analytical data show that the NPicO complexes have the formulae $\mathrm{La}(\mathrm{NPicO})_{5}$ $\left(\mathrm{ClO}_{4}\right)_{3}, \mathrm{Ln}_{4}(\mathrm{NPicO})_{9}\left(\mathrm{ClO}_{4}\right)_{6}(\mathrm{Ln}=\mathrm{Pr}, \mathrm{Nd}$, and $\mathrm{Gd})$ and $\mathrm{Ln}(\mathrm{NPicO})_{4}\left(\mathrm{ClO}_{4}\right)_{3}$ $(\mathrm{Ln}=\mathrm{Tb}, \mathrm{Dy}, \mathrm{Ho}$ and $\mathrm{Yb})$. The ligand to metal ratio is less than that in the corresponding complexes of 2,4-LutO (table 1).

Molar conductance data indicate that all the complexes behave as $1: 2$ electrolytes in nitromethane (Geary 1971) suggesting thereby that one of the three perchlorates is coordinated to the metal.

The IR frequencies for $\mathrm{NpicO}$ and its complexes along with the assignments are presented in table 2. The characteristic features of the IR spectra are (i) the $\mathrm{N}-\mathrm{O}$ stretching frequency of the ligand occurring at $1275-1300 \mathrm{~cm}^{-1}$ as a strong and broad band split into a strong and sharp band at $1295 \mathrm{~cm}^{-1}$ and a shoulder at $1275 \mathrm{~cm}^{-1}$ in all complexes except the La-complex, where only a band at $1295 \mathrm{~cm}^{-1}$ results, (ii) increase in the $\mathrm{C}-\mathrm{H}$ out-of-plane bending frequency of the ligand at $792 \mathrm{~cm}^{-1}$ by about $3-8 \mathrm{~cm}^{-1}$ and that of the ring stretch at $1520 \mathrm{~cm}^{-1}$ by about $5 \mathrm{~cm}^{-1}$ and (iii) bands that are assignable to both ionic and coordinated perchlorate groups.

Suszko and Szafran (1962) have found that the N-O of NPicO in benzene occurs at $1300 \mathrm{~cm}^{-1}$. In view of this, a negative shift of the $v_{\mathrm{N}-0}$ by about $5 \mathrm{~cm}^{-1}$ appearing in the complexes of $\mathrm{NpicO}$, indicates the coordination of the ligand through the oxygen of the $\mathrm{N}-\mathrm{O}$ group. The splitting of the $v_{\mathrm{n}-\mathrm{O}}$ in the complexes of lanthanides other than $\mathrm{La}$, can be taken to mean bridged structures in these complexes (Isobe et al 1974). A similar observation was made by Ramakrishnan and Soundararajan (1977) in the lanthanide iodide complexes of 2,6-LutO. The $v_{\mathrm{N}-\mathrm{O}}$ in these complexes being less than that in the corresponding complexes of 2,4-LutO $\left(\sim 7 \mathrm{~cm}^{-1}\right.$ ) (Navaneetham and Soundararajan 1979) suggests a weaker metalligand bond. This may be due to the electron-withdrawing nature of $\mathrm{NO}_{2}$ group coupled with the absence of back bonding.

The increase in $\mathrm{C}-\mathrm{H}$ out-of-plane bending and ring stretch reveals that the elestron density flows from the aromatic ring to the metals ion upon coordination.

The presence of a coordinated perchlorate group having $C_{3 v}$ symmetry is shown by the appearance of bands at $1158,1030,920$ and $648 \mathrm{~cm}^{-1}$ in the IR spectra (Hathaway and Underhill 1961 ; Hathaway et al 1963). The existence of bidentate perchlorate $\left(C_{20}\right)$ in complexes is rare (Rosenthal 1973). However, the absence of bands at $1170 \mathrm{~cm}^{-1}$ and at $928 \mathrm{~cm}^{-1}$ in the IR spectra indicate the absence of the bidentate perchlorate group (Rosenthal 1973). Ionic perchlorate has four fundamental modes of vibration, two of which are active in the IR between $1075-1100 \mathrm{~cm}^{-1}$ for $v_{3}$ and at $626 \mathrm{~cm}^{-1}$ for $v_{4}$.

The IR speztra of the NpicO complexes (table 2) show two bands, one in the range $1095-1100 \mathrm{~cm}^{-1}$ and the other at $625 \mathrm{~cm}^{-1}$ which have been assigned to the $v_{3}$ and $v_{4}$ vibrations respectively, of the perchlorate group ( $T_{d}$ symmetry). Also evidence for the presence of the coordinated perchlorate group $\left(C_{30}\right)$ is revealed by two bands-one in the region $1135-1155\left(v_{4}\right)$ and the other at $638 \mathrm{~cm}^{-1}\left(v_{3}\right)$. The other bands at 940 and $1030 \mathrm{~cm}^{-1}$, probably merge with the ligand bands 
Lanthanide perchlorate complexes

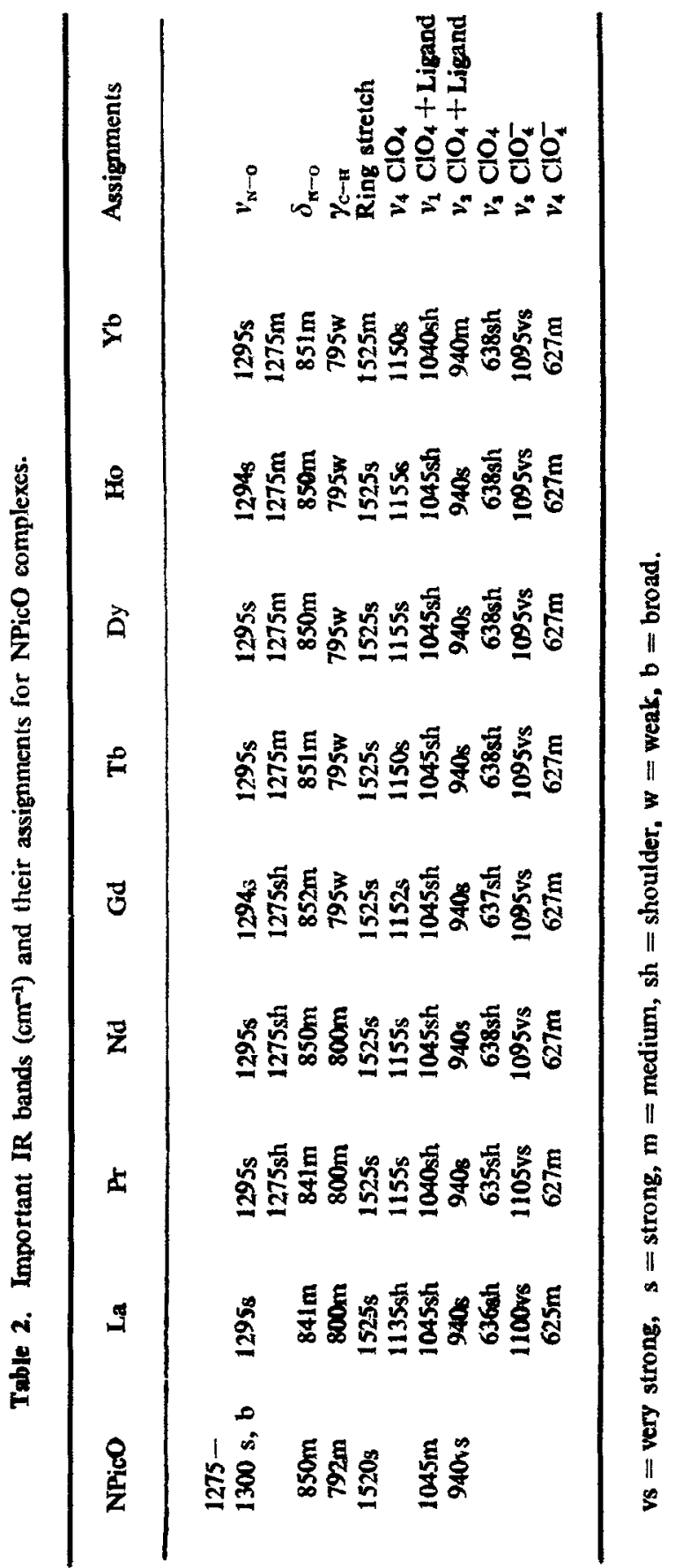


occurring in the same regions. As there are no bands at $1170 \mathrm{~cm}^{-1}$ and at $928 \mathrm{~cm}^{-1}$ we conclude that the bidentate perchlorate groups are absent. These assignments indizating the presence of perchlorate groups of both $T_{1}$ and $C_{3 v}$ symmetries are in line with the $1: 2$ elestrolytic conductivity evidence for the presence of one coordinated perchlorate group and two ionic perchlorate groups.

The proton NMR spectra of the diamagnetic $\mathrm{La}^{+3}$ complex are sharp and well resolved. The doublet occurring at $1 \cdot 77 \tau$ in the free ligand corresponds to the $6-\mathrm{H}$ signal, and that at $1.94 r$ is due to the $5-\mathrm{H}$. The singlet at $1 \cdot 83 \tau$ corresponds to the $3-\mathrm{H}$. The shifts in the ring proton signals of the ligand $(7 \mathrm{~Hz}$ for $6-\mathrm{H}, 4 \mathrm{~Hz}$ for $5-\mathrm{H}$ and $3-\mathrm{H}$ ) arise from a deshielding of the protons due to the drainage of the eleztron density from the ligand to the metal ion on coordination of the $\mathrm{N}$-oxide group.

The electronic spectra in nitro-methane indicate that the shapes of the hyper. sensitive bands

$$
{ }^{4} I_{8 / 2} \rightarrow{ }^{4} G_{5 / 2},{ }^{2} G_{7 / 2} \text { for } \mathrm{Nd}^{+3} \text { complex and }{ }^{5} I_{8} \rightarrow{ }^{5} G_{6},{ }^{5} F \text { for } \mathrm{Ho}^{+3}
$$

complex resemble those of the six coordinate complexes studied by Karnaker (1967).

\section{Bonding and coordination number}

The proton NMR data along with the IR data for the complexes indicate the coordination of the ligand through the oxygen of the $\mathrm{N}-\mathrm{O}$ group and the IR data suggest a weaker metal-ligand bond compared to that in the corresponding complexes of 2,4-LutO. The $1: 2$ electrolytic conductance along with the IR and electronic spectral data point to a coordination number of 6 in all the complexes with the possibility of an aromatic amine oxide bridged structure for all the complexes except the La-complex.

\section{Acknowledgements}

One of the authors (NSN) thanks the University Grants Commission, New Delhi, for a fellowship under the Faculty Improvement Programme.

\section{References}

Geary W J 1971 Coord. Chem. Rev. 781

Hathaway B J and Underhill A E $1961 \mathrm{~J}$. Chem. Soc. p. 3091

Hathaway B J, Hillah D G and Hudson M J $1963 \mathrm{~J}$. Chem. Soc. p. 4586

Isobe T, Matsuoka J, Kida S and Misumi S 1974 Mem. Fac. Soc. Sci. Kyushu Univ. Ser. C. Chem. 9115

Karayannis N M, Mikulski C M and Pytlewski L L 1974 Chim. Chronica 3121

Karraker D G 1967 Inorg. Chem. 61863

Katritzky A R, Randell E W and Sutton L E 1957 J. Chem. Soc. p. 1769

Kolthoff I M and Elwing P J 1963 Treatise on analytical chemistry Part II (New York : Interscience) 857

Koppikar D K and Soundararajan S 1975 J. Indian Inst. Sci. 57461 
Koppikar D K, Sivapullaiah P V, Ramakrishnan L and Soundararajan S 1978 Structure and Bonding 34150

Navanectham N S and Soundararajan S 1979 Proc. Indian Acad. Sci. A 88131

Ochiai E $1953 \mathrm{~J}$. Org. Chem. 18548

Ramakrishnan L and Soundararajan S 1977 Monatsh. Chem. 108225

Rosenthal $1973 \mathrm{~J}$. Chem. Edn. 50331

Suszko J and Szafran M 1962 Bull. Acad. Polon. Sci. Ser. Sci. Chim. 10233

Suszko J and Szafran M 1963 CA 58 7519d

Welcher F J 1947 Organic analytical reagents (New York : van Nostrand) 